\title{
Examination of different preparations of human placental plasma membrane for the binding of insulin, transferrin and immunoglobulins
}

\author{
M. Davies, J. E. Parry* and R. G. Sutcliffe \\ Institute of Genetics and *Institute of Virology, Glasgow University, Church Street, \\ Glasgow G11 5JS, U.K.
}

\begin{abstract}
Summary. Plasma membrane was prepared from human placental tissue by two standard methods. The preparations, termed PVM and PPM, examined by electron microscopy and polyacrylamide gel electrophoresis, were characterized with respect to their binding properties for insulin, transferrin, $\alpha_{2}$-macroglobulin and the immunoglobulins, $\operatorname{IgM}$ and $\operatorname{IgG}_{1}$. By means of sucrose density-gradient centrifugation, it was possible to fractionate the PVM into two distinct fractions. The first fraction, under the conditions used, was heavier (density $>1.080 \mathrm{~g} \cdot \mathrm{cm}^{-3}$ ) and was obtained as a pellet. It bound transferrin and IgM and had low specific activities for $5^{\prime}$-nucleotidase and for the binding of $\operatorname{IgG}_{1}$. The lighter fraction (density range $1 \cdot 048-1.050 \mathrm{~g} \cdot \mathrm{cm}^{-3}$ ) had a high specific activity for $5^{\prime}$-nucleotidase and for $\operatorname{IgG}_{1}$ binding. Transferrin and IgM did not bind to this fraction. Insulin bound to both the fractions with comparable levels of specific binding activity, while $\alpha_{2}$-macroglobulin binding was undetectable. The PPM preparation was found to have binding properties similar to those of the light fraction of PVM.
\end{abstract}

\section{Introduction}

The placenta, the physical barrier between the maternal and fetal circulations, exhibits a wide range of membrane phenomena including the binding of active molecules such as insulin (Posner, 1974; Harrison et al. 1977), transferrin (Balfour \& Jones, 1977; Faulk \& Galbraith, 1979) and immunoglobulins (Faulk, Jeannet, Creighton \& Carbonara, 1974; Matre, Tonder \& Endresen, 1975; McNabb, Koh, Dorrington \& Painter, 1976). The preparation of membrane fractions from this tissue has been described in the literature (Smith, Brush \& Luckett, 1974; Snary, Woods \& Crumpton, 1976). The method of Snary et al. (1976) employed a mechanical shearing step of the placental tissue and the resultant membrane preparation could have been derived from several cell types, although the trophoblast was presumably predominant because there was a substantial lack of HLA antigens (Goodfellow, Barnstable, Bodmer, Snary \& Crumpton, 1976). In the method of Smith et al. (1974), gentle washing was used to extract placental villous surface membrane, presumed to be the brush-border membrane from the maternal-facing surfaces of the syncytiotrophoblast. The justification of this technique was based on electron microscopic studies, which indicated that the chorionic villous surface was almost entirely free of the microvilli after the washing procedure and that little or no cellular damage was visible.

Since membrane studies reported in the literature have used one of these two methods, we investigated whether the membranes prepared by these different techniques were homogeneous and comparable with regard to their binding characteristics for insulin, transferrin and the immunoglobulins, $\operatorname{IgM}$ and $\operatorname{IgG}_{1}$. 


\section{Materials and Methods}

\section{Placental membrane preparations}

Placental villous surface membrane. This preparation (PVM) was produced by the method of Smith et al. (1974). Briefly, a fresh term placenta, from which the cord and membranes had been removed, was cut into small pieces and washed rapidly in ice-cold $0.11 \mathrm{M}$-calcium chloride followed by ice-cold saline $(9 \mathrm{~g} \mathrm{NaCl} / 1)$. The washed tissue was placed in saline and agitated for $30 \mathrm{~min}$ at $4^{\circ} \mathrm{C}$. The saline was removed and centrifuged at $800 \mathrm{~g}$ for $10 \mathrm{~min}$. The supernate was re-centrifuged, first at $10000 \mathrm{~g}$ for $5 \mathrm{~min}$ and then at $100000 \mathrm{~g}$ for $30 \mathrm{~min}$. The resulting pellet, of placental villous surface membrane (PVM), was re-suspended using a tight-fitting glass homogenizer, and washed in saline by centrifugation at $100000 \mathrm{~g}$ for $30 \mathrm{~min}$.

Placental plasma membrane. This PPM preparation was prepared by the method of Snary et al. (1976). The placental tissue removed from the membranous sheet of a fresh term placenta, was cut into small pieces and washed in ice-cold $0.15 \mathrm{M}-\mathrm{NaCl}$ in $10 \mathrm{~mm}$-Tris- $\mathrm{HCl}$ buffer, $\mathrm{pH}$ 7.3. The washed pieces were forced through a metal grid by means of a mechanical press, and the resultant filtrate passed through muslin. The filtered material was centrifuged at $4000 \mathrm{~g}$ for $15 \mathrm{~min}$ and the supernate was re-centrifuged at $20000 \mathrm{~g}$ for $30 \mathrm{~min}$. The pellet was re-suspended in $36 \%\left(\mathrm{w} / \mathrm{v}\right.$ ) (density $1.08 \mathrm{~g} \cdot \mathrm{cm}^{-3}$ ) sucrose in $10 \mathrm{~mm}$-Tris- $\mathrm{HCl}$ buffer, $\mathrm{pH} 7 \cdot 3$, overlaid with an equal volume of $25 \%\left(\mathrm{w} / \mathrm{v}\right.$ ) (density $1.041 \mathrm{~g} \cdot \mathrm{cm}^{-3}$ ) sucrose and centrifuged at $60000 \mathrm{~g}$ for $16 \mathrm{~h}$ in a $10 \times 10$ titanium rotor in an MSE Superspeed 65 centrifuge. The material at the interface was collected and washed free of the sucrose by centrifugation at $100000 \mathrm{~g}$ for $30 \mathrm{~min}$ in 10 mM-Tris- $\mathrm{HCl}$ buffer, $\mathrm{pH} \mathrm{7.3.} \mathrm{The} \mathrm{final} \mathrm{pellet} \mathrm{of} \mathrm{placental} \mathrm{plasma} \mathrm{membrane} \mathrm{was} \mathrm{re-suspended}$ in buffer using a tight-fitting glass homogenizer.

\section{Membrane characteristics}

The two membrane preparations were subjected to a variety of analyses (see below for details). Since the PPM was prepared by means of sucrose density gradient centrifugation, the PVM was treated similarly to yield two membranous fractions, termed the pellet fraction and Fractions $4+5$, respectively. The relationship of these fractions to PVM and PPM is represented in Text-fig. 1.

Sucrose gradient centrifugation. Membrane preparations in $10 \mathrm{~mm}$-Tris-HCl buffer, $\mathrm{pH}$ $7 \cdot 3$, were layered onto a continuous gradient of $10-40 \%(\mathrm{w} / \mathrm{v})$ (density range $1.028-1.08$ $\mathrm{g} \cdot \mathrm{cm}^{-3}$ ) sucrose in $10 \mathrm{~mm}$-Tris- $\mathrm{HCl}$ buffer, $\mathrm{pH} 7.3$ and centrifuged at $60000 \mathrm{~g}$ for $16 \mathrm{~h}$. Fractions $(1 \mathrm{ml})$ were collected by puncturing the bottom of the centrifuge tubes.

Protein estimation. The protein content of the membrane fractions was estimated by the method of Lowry, Rosebrough, Farr \& Randall (1951) using bovine serum albumin (BSA) as the standard.

Albumin profiles. Aliquots of the fractions from the sucrose density gradient centrifugation were placed in wells in a $1 \%(\mathrm{w} / \mathrm{v})$ agarose gel, containing appropriately diluted sheep antiserum against whole normal human serum. The plates were subjected to electrophoresis at $3 \mathrm{~mA}$ and at

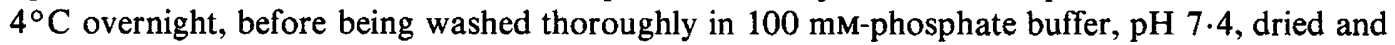
stained for protein in $0.2 \%$ Coomassie Blue. The albumin precipitin peaks were quantitated by estimating the area under the peaks.

Enzyme marker estimation. The 5'-nucleotidase (EC 3.1.3.5) activity in the preparations was assessed by means of a commercially available assay kit (Sigma Chemical Co., St Louis, Missouri, U.S.A.).

Electron microscopy. The membrane preparations were centrifuged at $100000 \mathrm{~g}$ for $30 \mathrm{~min}$, washed in two changes of phosphate-buffered saline (PBS: $0.16 \mathrm{M}-\mathrm{NaCl}$ in $5 \mathrm{mM}$-potassium phosphate, $\mathrm{pH} 7.5$ ) (5 min each) and fixed for $60 \mathrm{~min}$ in $2.5 \%$ phosphate-buffered glutaraldehyde at room temperature. The pellet, washed in three changes of PBS, was post-fixed 


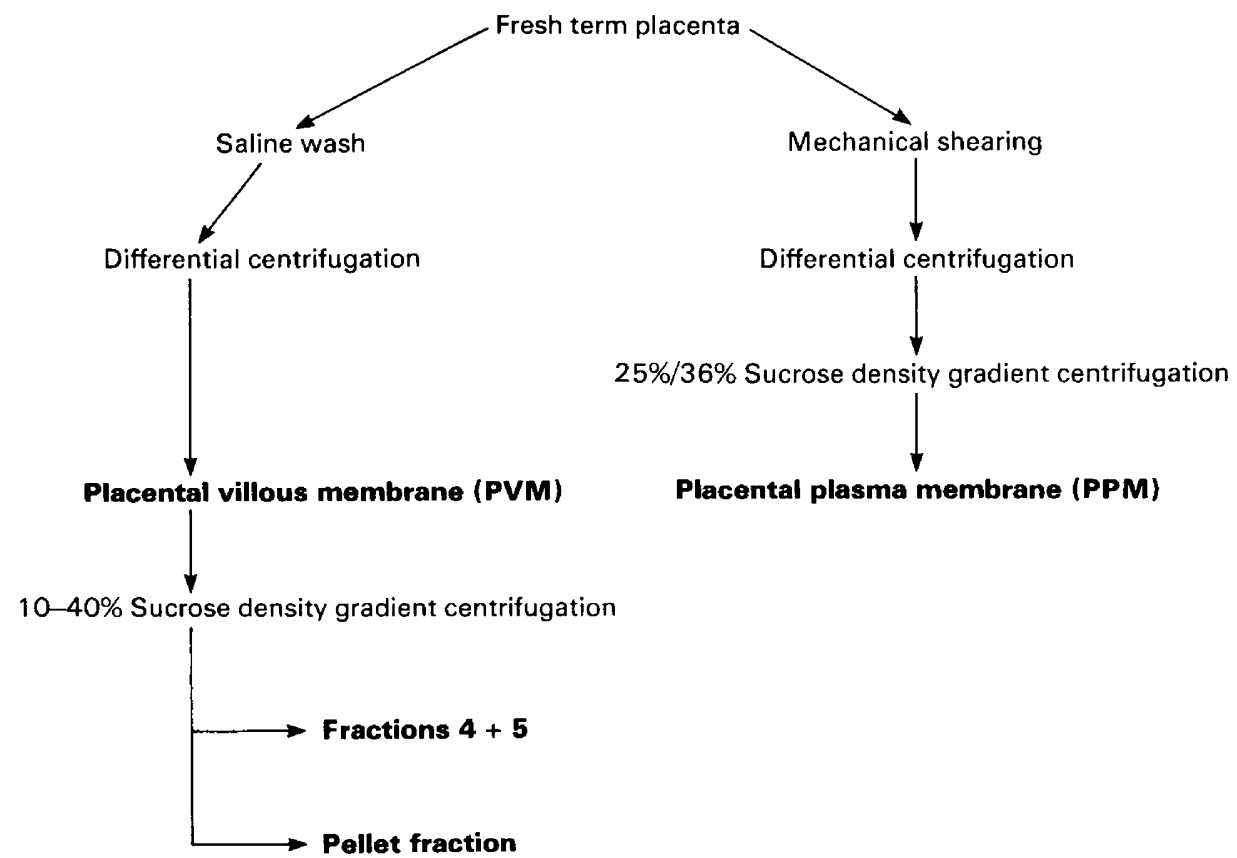

Text-fig. 1. Flow diagram of the relationship between the different placental membrane fractions.

in $1 \%$ phosphate-buffered osmium tetroxide for $60 \mathrm{~min}$. After washing in three changes of PBS, the pellet was dehydrated via a series of graded ethanols, up to $100 \%$. The final change was replaced gradually by Epon (Agar Aids, Cambridge Road, Stanstead, Essex) over 48 h. After two changes of fresh Epon and polymerization for $72 \mathrm{~h}$ at $65^{\circ} \mathrm{C}$, the resin blocks were sectioned on an LKB Ultrotome II. Sections $60-80 \mathrm{~nm}$ thick were collected on copper grids, stained with uranyl acetate and lead citrate and examined at $80 \mathrm{kV}$ in a Siemens Elmiskopf 101.

Polyacrylamide gel electrophoresis. Samples of membrane material (see 'Results' for details) were subjected to electrophoresis by a method similar to that described by Laemmli (1970). Briefly, slab gels with a polyacrylamide gradient of $4.5-15 \%$ were prepared in $0.38 \mathrm{M}$-Tris- $\mathrm{HCl}$ buffer, $\mathrm{pH} 9 \cdot 4$, containing $1 \%$ (w/v) sodium dodecyl sulphate (SDS). The 13-14 cm running gel was overlaid with a spacer gel of $4 \%$ polyacrylamide in $0.12 \mathrm{M}$-Tris- $\mathrm{HCl}$ buffer, $\mathrm{pH} 6.7$, containing $1 \%(\mathrm{w} / \mathrm{v})$ SDS. The membrane samples were solubilized by heating to $100^{\circ} \mathrm{C}$ for 3 $\mathrm{min}$ in a mixture containing, as final concentrations, $4 \mathrm{mg}$ membrane protein $/ \mathrm{ml}, 1.2 \%(\mathrm{v} / \mathrm{v})$ $\beta$-mercaptoethanol, 10\% (v/v) glycerol and 3.2\% (w/v) SDS. A $40 \mu$ solubilized membrane sample was applied to the gels, which were electrophoresed in $0.056 \mathrm{M}$-glycine in 0.052 $\mathrm{M}$-Tris- $\mathrm{HCl}$ buffer, containing $0.1 \%(\mathrm{w} / \mathrm{v}) \mathrm{SDS}$, for $4-5 \mathrm{~h}$ at a constant current of $40 \mathrm{~mA}$ per gel. The gels were stained for protein with $0.2 \%(\mathrm{w} / \mathrm{v})$ Coomassie blue in methanol:glacial acetic acid $(5: 1, \mathrm{v} / \mathrm{v})$ for $1 \mathrm{~h}$ at room temperature. The gels were de-stained in methanol:glacial acetic acid $(5: 1 \mathrm{v} / \mathrm{v})$ for $1 \mathrm{~h}$ and then in $10 \%(\mathrm{v} / \mathrm{v})$ acetic acid until the background was colourless.

Radiolabelling of proteins. ${ }^{125} \mathrm{I}$ was bound to the proteins by the chloramine $\mathrm{T}$ method as described by Hunter \& Greenwood (1962) using 250-500 $\mu \mathrm{Ci}$ carrier-free $\mathrm{Na}^{125} \mathrm{I}, 5-10 \mu \mathrm{g}$ protein, $5 \mu \mathrm{g}$ chloramine $\mathrm{T}$ and $12 \mu \mathrm{g}$ sodium metabisulphite in a volume of $45 \mu \mathrm{l}$ containing 0.2 $\mathrm{M}$-potassium phosphate. The resultant specific activity of labelling was in the range $5-16 \mu \mathrm{Ci} / \mu \mathrm{g}$ protein. The proteins used for radiolabelling were obtained from a variety of sources. Intact porcine insulin, the insulin $\mathrm{A}$ and $\mathrm{B}$ chains and human transferrin were obtained from the Sigma 
Chemical Co. IgM was prepared by euglobulin precipitation and column chromatography (Heide \& Schwick, 1978) from the serum of a patient with a Waldenström's macroglobulinaemia (supplied by Dr D. R. Stanworth, Department of Immunology, University of Birmingham, U.K.). Purified $\mathrm{IgG}_{1}$, from the serum of a patient with multiple myeloma, was also given by Dr Stanworth. Both immunoglobulin preparations were checked for purity by polyacrylamide gel electrophoresis. The $\alpha_{2}$-macroglobulin was purified as described by Sutcliffe, Kukulska-Langlands, Coggins, Hunter \& Gore (1980).

Preparation of $F c$ fragments from $\operatorname{Ig} G_{1}$. Fc fragments were prepared from $\operatorname{IgG}_{1}$ by cleavage with mercuripapain (Sigma Chemical Co.) using the method of Porter (1959). The digestion products were separated on DEAE-Sepharose CL6B (Pharmacia, Sweden) using the buffer system of Franklin (1960) and on CM-Sepharose CL6B using the buffer system of Porter (1959). Purity was analysed by $10-20 \%$ polyacrylamide-SDS gradient-gel electrophoresis and on Ouchterlony plates using anti-Fc and anti-Fab antisera (Behring Institute, Hoechst Pharmaceuticals).

Binding assays. These were performed by a method similar to that described by Marshall, Underwood, Voina, Foushee \& Van Wyk (1974) and Harrison, Billington, East, Nichols \& Clark (1978). Briefly, the reaction mixture consisted of $100 \mu$ of an homogenized membrane suspension $(100-400 \mu \mathrm{g}), 200 \mu \mathrm{l}$ bovine serum albumin $(5 \mathrm{mg} / \mathrm{ml}), 200 \mu \mathrm{l} 0.1 \mathrm{M}$-phosphate buffer, $\mathrm{pH} \mathrm{7.4}$, and variable quantities of the ${ }^{125}$ I-labelled protein $(15-50 \mathrm{ng})$. The reaction mixture was incubated at $4{ }^{\circ} \mathrm{C}$ for $20 \mathrm{~h}$ and centrifuged at variable speeds from 3000 to 100000 $\boldsymbol{g}$ for $30 \mathrm{~min}$. The radioactivity associated with the pellet and the supernate was estimated.

\section{Results}

\section{Purification of plasma membrane}

The two placental membrane samples, PVM and PPM, were examined throughout their preparation for enrichment of the plasma membrane enzyme marker, $5^{\prime}$-nucleotidase. Under the conditions of the assay, the PVM preparation showed a 9- to 12 -fold increase in specific activity compared with that in the saline-washed starting material, while the PPM preparation exhibited 7- to 9-fold. more activity than in the mechanically-disrupted filtrate. The final membrane samples were examined on $4 \cdot 5-15 \%$ polyacrylamide gradient gel electrophoresis, which revealed that both preparations were heterogeneous mixtures of polypeptides, different from each other and from their respective starting materials (PI. 1, Fig. 1). Examination of the preparations by electron microscopy showed that both samples were reasonably homogeneous, consisting of characteristic membrane vesicles, with a typical bilayer structure (Pl. 1, Figs 2 and 3; Pl. 2, Figs 4 and 5). The PVM preparation was associated with a large amount of amorphous material (Pl. 2, Figs 4 and 5) which could be part of the fibrinoid layer known to cover the microvilli (Currie \& Bagshawe, 1967); the nature of this material is being examined.

The protein profile for PVM (Text-fig. 2) showed a U-shaped distribution, with approximately $30 \%$ of the applied protein associated with the pellet and $43 \%$ with the lighter fractions (density $<1.04 \mathrm{~g} \cdot \mathrm{cm}^{-3}$ ). The $5^{\prime}$-nucleotidase activity (Text-fig. 2) was distributed throughout the gradient with a peak of high specific activity associated with Fractions 4 and 5 (density range $1.048-1.05 \mathrm{~g} \cdot \mathrm{cm}^{-3}$ ), which contained only $5.5 \%$ of the original PVM protein applied to the gradient. The pellet also showed enzyme activity, but it was of lower specific activity. Application of PPM preparation, obtained from the interface of a $36 \% / 25 \%$ discontinuous sucrose gradient, to the continuous gradient (Text-fig. 2) showed distribution throughout the gradient, with approximately $27 \%$ of the applied protein associated with the $1.048-1.05 \mathrm{~g} \cdot \mathrm{cm}^{-3}$ density range which also showed a peak of high specific enzyme activity (Text-fig. 2). The serum albumin profile (Text-fig. 2) revealed that albumin was measurable only in the lighter fractions of PVM and PPM (density $<1.045 \mathrm{~g} \cdot \mathrm{cm}^{-3}$ ), although a small amount of 
material appeared to be associated with or trapped in the PVM pellet. After preparation of the PVM by this density-gradient centrifugation step, the pellet and the Fractions $4+5$ with high specific activity for 5 -nucleotidase were examined under the electron microscope. Both fractions contained membranous vesicular material (Pl. 2, Figs 6 and 7) similar in nature to the unfractionated PVM and the PPM preparations. The pelleted fraction was associated with a large amount of amorphous material also seen in the unfractionated PVM preparation. The membrane in Fractions $4+5$ was cleaner in appearance and was similar to the PPM preparation. Examination of the two fractions on polyacrylamide gels showed that the samples were similar to each other but did differ at certain bands (Pl. 1, Fig. 1). For example, the pellet fraction contained a major protein band with an apparent molecular weight of 35000 , which was absent from the material in Fractions $4+5$.

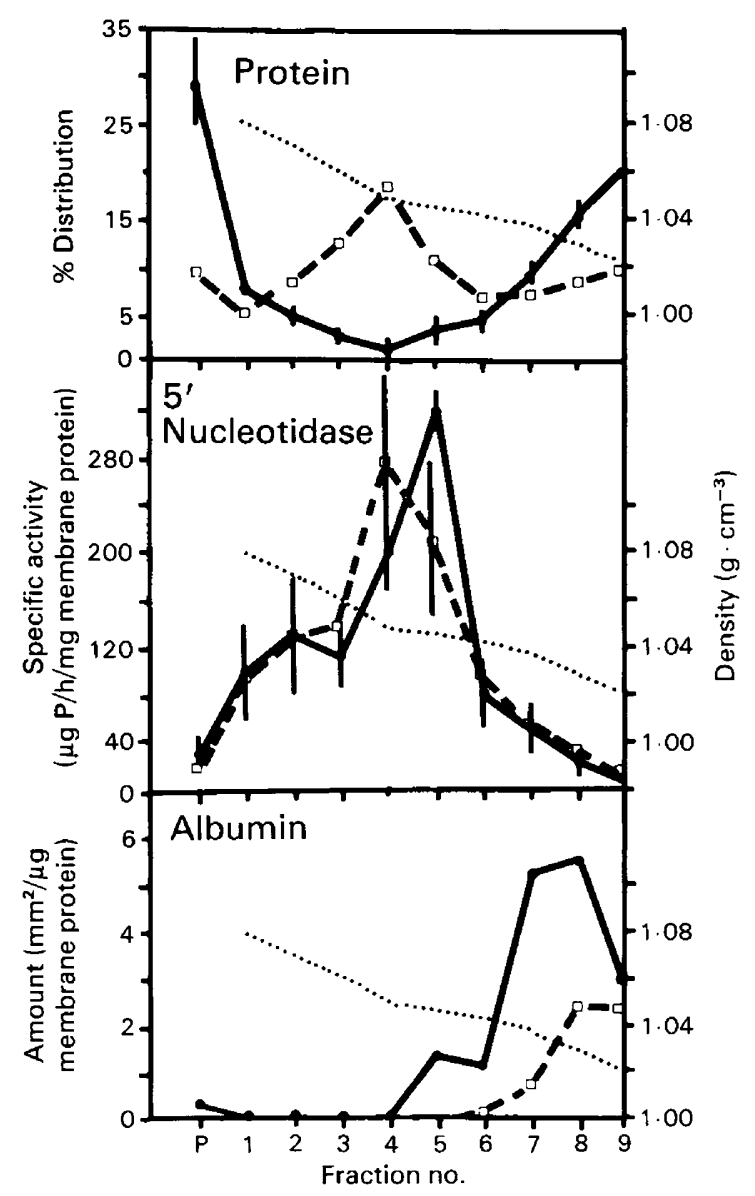

Text-fig. 2. Examination of fractions from sucrose density gradient centrifugation of PVM (O) and PPM $(\square)$ preparations. $P=$ pellet. Values are given as mean \pm s.e.m. for 5 observations.

\section{Binding properties of the membrane preparations}

In the initial experiments, insulin, immunoglobulins $\operatorname{IgG}_{1}$, transferrin and alpha ${ }_{2}$-macroglobulin were labelied with ${ }^{125} \mathrm{I}$ and incubated with aliquots of the PVM preparation before sucrose density gradient centrifugation. Fractions were collected and examined for the binding of the various proteins. The membrane binding of insulin was examined using intact insulin 
molecules as well as the separate A and B chains. Intact insulin molecules bound with two peaks of high specific binding activity, one associated with the pellet and heavy fractions, and the other with Fractions $4+5$ (Text-fig. 3a). There was no detectable binding of the separate A and B chains. $\mathrm{IgG}_{1}$ bound throughout the gradient, with a peak of high specific binding activity associated with Fractions $4+5$ (Text-fig. $3 b$ ). The binding of IgM, which was much less than that of $\mathrm{IgG}_{1}$, was associated only with the pellet and the heaviest fractions from the gradient (Text-fig. 3c). There was no apparent binding of $\alpha_{2}$-macroglobulin but a small amount of transferrin was associated primarily with the pellet and heaviest fractions (Text-fig. 3d).

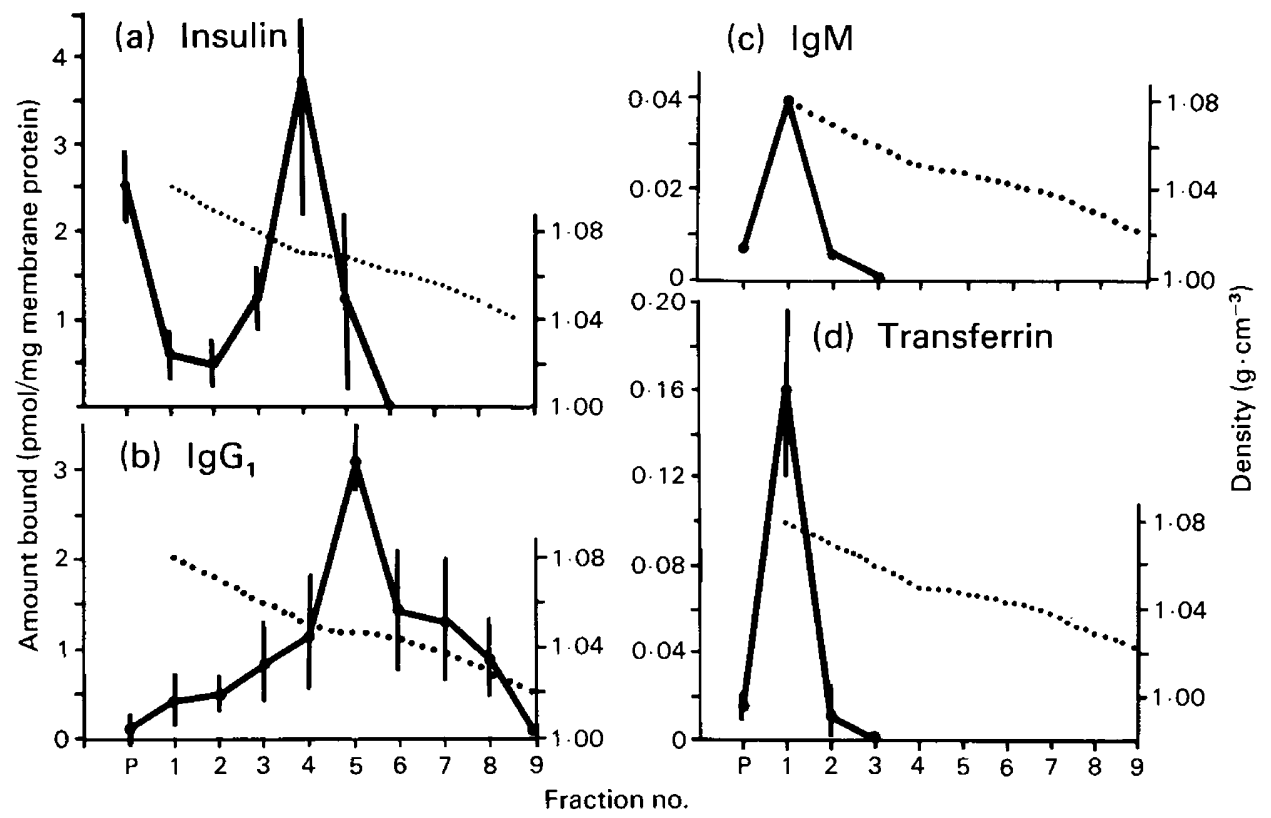

Text-fig. 3. The distribution of membrane-associated (a) insulin, (b) $\operatorname{IgG}_{1}$, (c) IgM and (d) transferrin on a sucrose density-gradient centrifugation of PVM preparation. $\mathbf{P}=$ pellet. The values are mean \pm s.e.m. for 5 observations.

\section{PLATE 1}

Fig. 1. Sodium dodecyl sulphate-polyacrylamide gel electrophoresis of placental plasma membrane preparations. A, PVM preparation, saline wash; B, final membrane pellet of PVM; C, PPM preparation, crude placental homogenate; $D$, final membrane pellet; $E$, sucrose gradient centrifugation of PVM, pelleted membrane material; F, non-pelleted membrane material (Fractions $4+5$ ) of sucrose gradient centrifugation of PVM; G, normal human serum. The arrows represent the molecular weight markers.

Fig. 2. Electron micrograph of the placental plasma membrane (PPM) preparation. $\times 29000$.

Fig. 3. Higher power of Fig. 2; the structure arrowed represents a membrane junction, possibly a desmosome. $\times 66000$.

\section{PLATE 2}

Fig. 4. Electron micrograph of the placental villous membrane (PVM) preparation. $\times 29000$.

Fig. 5. Higher magnification of Fig. 4. $\times 66000$.

Figs 6 and 7. Electron micrograph of membrane fractions from the sucrose density gradient centrifugation of PVM. Fig. 6. Non-pelleted membrane material (Fractions $4+5$ ). Fig. 7 . Pelleted membrane fraction. $\times 29000$. 


\section{PLATE 1}
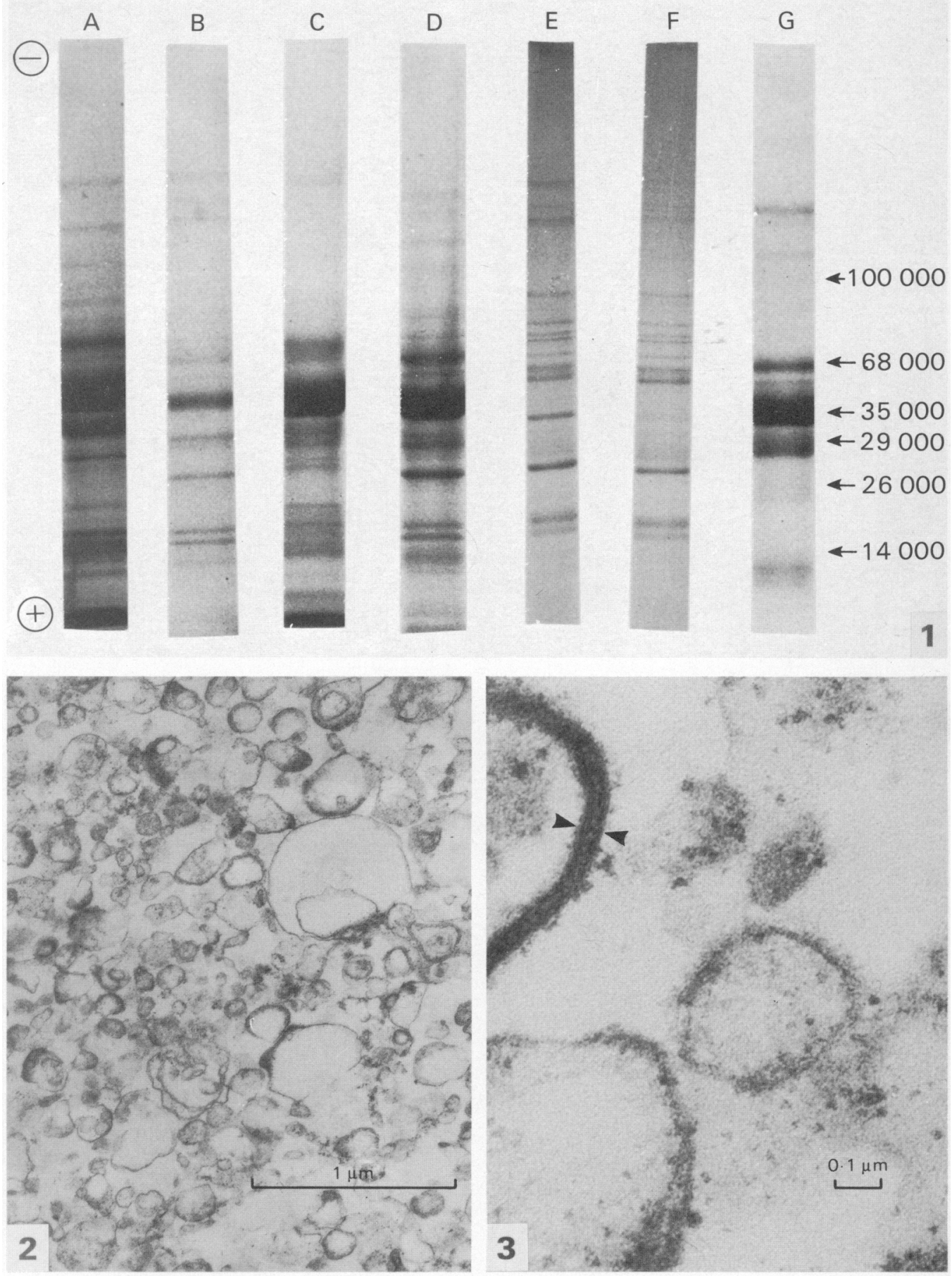

(Facing p. 320) 

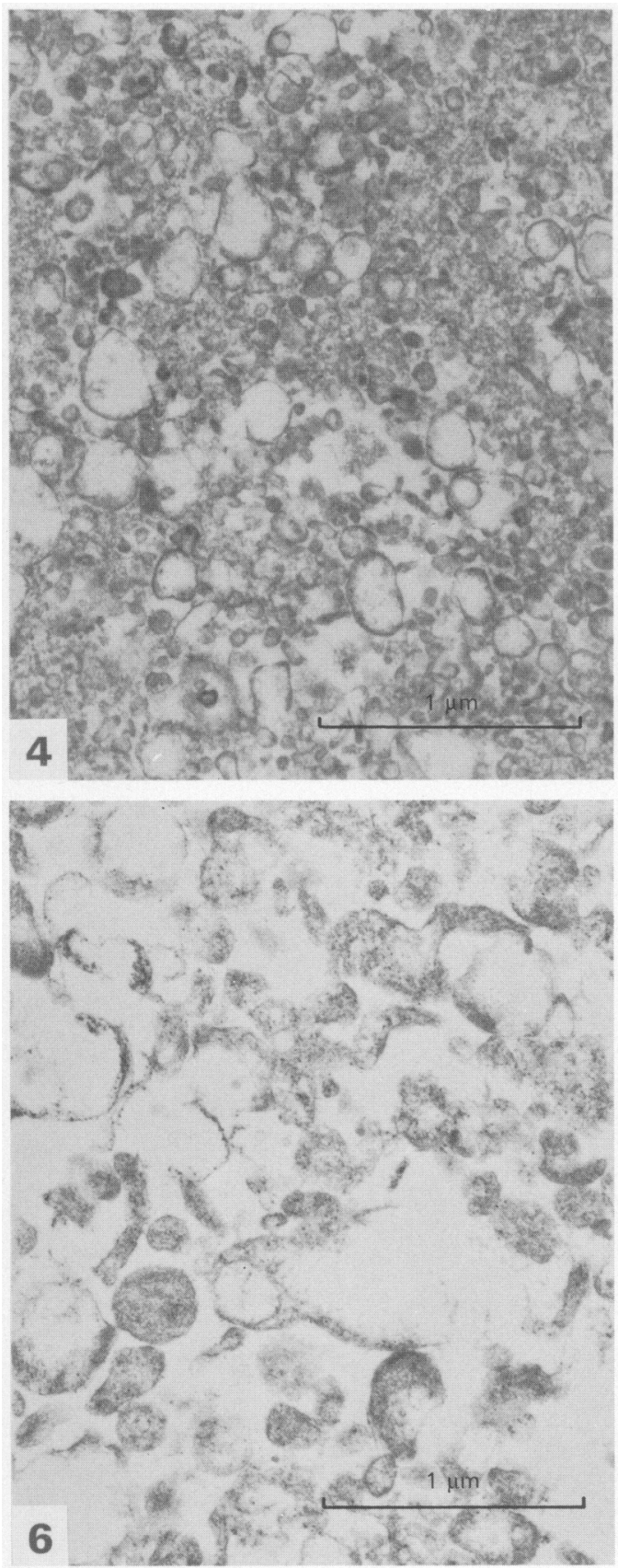
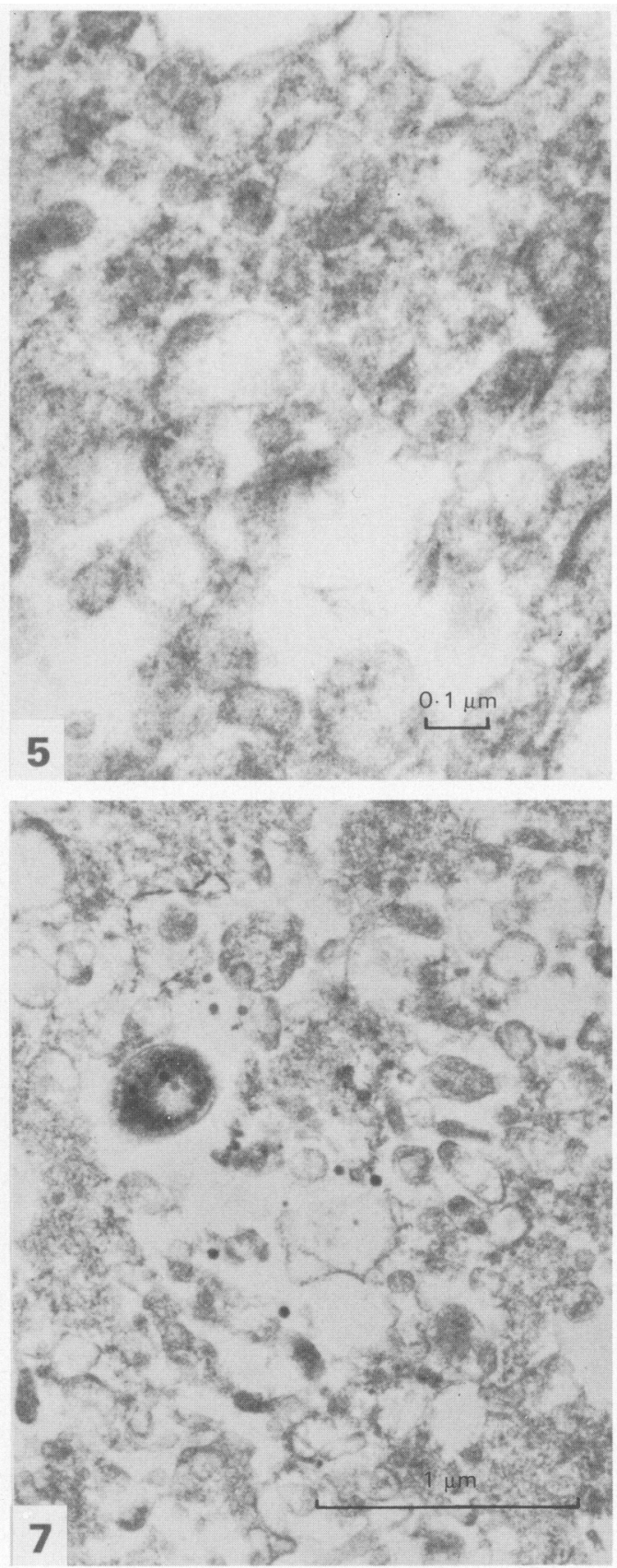
For comparative purposes the binding of insulin, $\operatorname{IgG}_{1}$ and transferrin to the PPM, the unfractionated PVM, and the pellet fraction and Fractions $4+5$ from a sucrose density gradient of PVM were examined. The amounts of each of the radiolabelled proteins binding to the membranes varied considerably and were affected by the age of the preparation. Freshly prepared membranes showed higher degrees of binding than did samples that had been stored at $-20^{\circ} \mathrm{C}$. Although absolute binding values were not obtained in this assay, which was not performed under strict saturating conditions, data were compiled from several experiments and ranges are shown in Table 1 . The specificity of the binding of the proteins was tested, although non-specific binding had been eliminated by performing the assays in the presence of a large excess of BSA. Unlike intact insulin, the separated insulin A and B chains did not bind to the membranes and the binding of ${ }^{125}$ I-labelled insulin was competitively inhibited in the presence of a large excess of non-radioactive insulin and unaffected in the presence of an excess of $\operatorname{IgG}_{1}$ (Table 2). Similarly, the membrane binding of $\operatorname{IgG}_{1}$ was inhibited by an excess of unlabelled $\mathrm{IgG}_{1}$ or the appropriate $\mathrm{Fc}$ fragment, but not by an excess of insulin (Tables 2 and 3). Similarly the binding of transferrin was specific with the majority of the labelled protein being displaced in the presence of an excess of unlabelled transferrin and unaffected by $\operatorname{IgG}_{1}$ and intact insulin (Table 3).

\section{Effect of variable centrifugal forces on binding characteristics}

The binding assays for placental membrane samples, as described in the literature (Marshall et al. 1974; Harrison et al. 1978), involve a period of incubation of the tracer protein with a

Table 1. Comparison of the amounts of proteins binding to the membrane preparations (compiled from 6 experiments)

\begin{tabular}{|c|c|c|c|}
\hline \multirow[b]{2}{*}{ Membrane preparation } & \multicolumn{3}{|c|}{$\begin{array}{c}\text { Protein binding } \\
\text { (pmol/mg membrane protein) }\end{array}$} \\
\hline & $\operatorname{IgG}_{1}$ & Insulin & Transferrin \\
\hline PPM & $9 \cdot 8-13 \cdot 0$ & $8 \cdot 3-10 \cdot 7$ & - $^{*}$ \\
\hline \multicolumn{4}{|l|}{ PVM } \\
\hline Whole & $2 \cdot 7-4 \cdot 1$ & $1 \cdot 31-1 \cdot 89$ & 0.08 \\
\hline Pellet fraction from sucrose gradient & $0.01-0.25$ & $2 \cdot 1-2 \cdot 9$ & $0 \cdot 12-0.20$ \\
\hline Fractions $4+5$ from sucrose gradient & $2 \cdot 75-3 \cdot 40$ & $2 \cdot 25-5 \cdot 25$ & — \\
\hline
\end{tabular}

* Not measurable.

Table 2. The specificity of binding of insulin and $\mathrm{IgG}_{1}$ (data from 6 experiments)

\begin{tabular}{|c|c|c|c|c|}
\hline \multirow[b]{3}{*}{ Membrane preparation } & \multicolumn{4}{|c|}{$\%$ inhibition of counts bound to membrane* } \\
\hline & \multicolumn{2}{|c|}{${ }^{125}$ I-labelled insulin } & \multicolumn{2}{|c|}{${ }^{129} \mathrm{I}_{\text {-labelled } \mathrm{IgG}_{1}}$} \\
\hline & Insulin & $\operatorname{IgG}_{1}$ & Insulin & $\mathrm{IgG}_{1}$ \\
\hline PPM & $82-85$ & 0 & 1 & $70-97$ \\
\hline \multicolumn{5}{|l|}{ PVM } \\
\hline Whole & $80-96$ & 0 & 0 & 45 \\
\hline Pellet fraction from sucrose gradient & $66-73$ & 0 & 8 & 20 \\
\hline Fractions $4+5$ from sucrose gradient & 71 & $-\dagger$ & $-\dagger$ & 73 \\
\hline
\end{tabular}

* Calculated from the formula: $(\mathrm{A}-\mathrm{B}) / \mathrm{A} \times 100$, where $\mathrm{A}$ is the amount of ${ }^{125}$ I-labelled protein bound in the absence of competitor and $\mathrm{B}$ is the amount of ${ }^{125}$ I-labelled protein bound in the presence of $1 \mu \mathrm{g}$ competitor.

$\dagger$ Not tested. 
Table 3. The specificity of binding of $\operatorname{IgG}_{1}$ and transferrin* (data from 6 experiments)

\begin{tabular}{|c|c|c|c|c|c|c|c|c|c|c|}
\hline \multirow[b]{4}{*}{ Inhibitor } & \multicolumn{10}{|c|}{$\%$ inhibition of binding of $\dagger$} \\
\hline & \multicolumn{3}{|c|}{${ }^{125}$ I-labelled $\mathrm{IgG}_{1}$} & \multicolumn{3}{|c|}{$\begin{array}{c}{ }^{125} \text { I-labelled } \\
\gamma \text { Fc fragment }\end{array}$} & \multicolumn{4}{|c|}{${ }^{125}$ I-labelled transferrin } \\
\hline & \multicolumn{3}{|c|}{ Dose of inhibitor (ng) } & \multicolumn{3}{|c|}{ Dose of inhibitor (ng) } & \multicolumn{4}{|c|}{ Dose of inhibitor (ng) } \\
\hline & 10 & 100 & 1000 & 10 & 100 & 1000 & 10 & 100 & 1000 & 10000 \\
\hline Intact $\operatorname{IgG}_{1}$ & $4-16$ & $0-11$ & $60-74$ & - & 一‡ & $64-97$ & 0 & 0 & 0 & 0 \\
\hline$\gamma \mathrm{Fc}$ fragment & $0-11$ & $1-22$ & $76-89$ & 一 & - & $72-100$ & 一 & - & 一‡ & 一‡ \\
\hline Intact insulin & 一 & 一 & $1-15$ & - & - & $0-32$ & 0 & 0 & $0-14$ & $0-10$ \\
\hline Transferrin & 一 & 一 & 一‡ & 一 & 一 & -‡ & 0 & $0-9$ & $30-56$ & $74-94$ \\
\hline
\end{tabular}

* $50 \mathrm{ng}{ }^{125}$ I-labelled protein were bound to $143 \mu \mathrm{g}$ protein from Fractions $4+5$ from sucrose density gradient centrifugation of a PVM preparation ( $\mathrm{IgG}_{1}$ and $\gamma \mathrm{Fc}$ fragment) and to $107 \mu \mathrm{g}$ protein from the pellet fraction from the same gradient (transferrin).

$\dagger$ Calculated from the formula: $(\mathrm{A}-\mathrm{B}) / \mathrm{A} \times 100$, where $\mathrm{A}$ is the amount of ${ }^{125}$ I-labelled protein bound in the absence of inhibitor, and $B$ is the amount of ${ }^{125} \mathrm{I}$-labelled protein bound in the presence of various amounts of the inhibitor.

$\ddagger$ Not tested.

membrane source followed by a low-speed centrifugation (3000-6000 g) to yield results based on the amount of radioactivity associated with the pellet and the supernate obtained. In the present studies, the radiolabelled proteins were incubated with membrane samples under standard conditions (see 'Materials and Methods'), but the reaction mixtures were subjected to a range of centrifugal forces $(3000-100000 \mathrm{~g}$ ), which revealed that the membrane preparations were a mixture of fractions that bound insulin and $\mathrm{IgG}_{1}$ and required different centrifugal forces in order to form into a pellet. The results, summarized in Table 4, show that the PVM (whole preparation) and the pellet fraction from the sucrose density gradients of PVM appeared to bind the insulin and the $\operatorname{Ig} G_{1}$ in a similar manner. Hence approximately $85 \%$ of these labelled proteins bound by the two preparations could be centrifuged into a pellet with a centrifugal force < $12000 \mathrm{~g}$ with only $14 \%$ being bound to a lighter fraction that required higher centrifugal forces $(25000-100000 \mathrm{~g})$ to form into a pellet. However, the other samples examined, PPM and the Fractions $4+5$ from the sucrose density-gradient separation of PVM, appeared similar to each other, and different from the other two preparations, since approximately $50 \%$ of the labelled proteins bound required large centrifugal forces $(25000-100000 \mathrm{~g}$ ) to ensure pellet formation.

Table 4. Summary of the effect of various centrifugal force $(g)$ on the binding assay (data from 9 experiments)

\begin{tabular}{|c|c|c|c|c|}
\hline \multirow[b]{3}{*}{ Membrane preparation } & \multicolumn{4}{|c|}{$\%$ of total protein bound } \\
\hline & \multicolumn{2}{|c|}{ Insulin } & \multicolumn{2}{|c|}{$\operatorname{IgG}_{1}$} \\
\hline & $3000-12000$ & $25000-100000$ & $3000-12000$ & $25000-100000$ \\
\hline PPM & 67 & 33 & 50 & 50 \\
\hline \multicolumn{5}{|l|}{ PVM } \\
\hline Whole & 84 & 16 & 78 & 22 \\
\hline Pellet fraction from sucrose gradient & 88 & 12 & 91 & 9 \\
\hline Fractions $4+5$ from sucrose gradient & 45 & 55 & 55 & 45 \\
\hline
\end{tabular}

* Calculated from the formula: $\mathrm{A} / \mathrm{B} \times 100$, where $\mathrm{A}$ is the amount of the protein bound to the membrane pellet over the range of centrifugal force examined and $B$ is the total amount of protein bound to the membrane pellet over the whole range of centrifugal force, $3000-100000 \mathrm{~g}$. 


\section{Discussion}

Electron microscopic studies revealed that the preparations of placental membranes obtained by the methods of Smith et al. (1974) and Snary et al. (1976) were similar at low and high magnifications and showed characteristic membrane vesicles with a bilayer structure. Analysis by SDS polyacrylamide gradient gel electrophoresis revealed a heterogeneous mixture of polypeptides with between 9 and 12 major protein bands in the membrane samples. Carlson, Wada \& Sussman (1976) have reported at least 26 major polypeptide bands for a membrane preparation of which 16 were major proteins and 10 glycoproteins. Similarly, Ogbimi, Johnson, Brown \& Fox (1979) have reported up to 21 discrete protein bands, with the major proteins ranging in apparent molecular weight from 34000 to 101000.

Although the PVM and PPM preparations in the present study exhibited morphological and electrophoretic similarities the binding activities of these two membrane preparations for IgG $_{1}$ and insulin were considerably different, with the PPM being 3.5-5 times more avid. The reason for this difference was not clear and was probably not due to the use of the gradient centrifugation, since the avidity of PVM was not improved by means of this step (Table 1). The greater binding of the PPM might be related to the fact that the method extracts membrane from both faces of the trophoblast rather than from the maternally-facing surface only. However, the higher binding of $\operatorname{IgG}_{1}$ to PPM (compared with PVM) may argue in favour of an enrichment of a membrane fraction from the microvilli which are expected to be rich in the syncytiotrophoblast Fc receptors. The more gentle extraction method for PVM may produce a subset of microvilli which are dissociated from the placenta in relation to a cycle of microvillous ageing, loss and regeneration.

Sucrose gradient centrifugation, a step in the preparation of PPM, was incorporated into the purification of PVM in an attempt to remove passively adsorbed serum proteins. This procedure was useful because most of the serum albumin was found at the top of the gradient. Moreover, the gradient yielded two regions (the pellet and Fractions $4+5$ ) which contain membrane detectable in the electron microscope. To study the protein-binding properties of these fractions, PVM was incubated with radiolabelled proteins (insulin, transferrin and immunoglobulin) before being applied to sucrose gradients. The results showed that both fractions of membrane bound insulin at similar levels and that the binding was specific using competitive inhibition as the criterion. However, the membrane fractions differed to a degree in their other binding properties. Transferrin was bound in detectable levels only in the pelleted membrane while the specific binding activity for $\operatorname{IgG}_{1}$ was 10 times greater for the membrane in Fractions $4+5$ compared with the pelleted fraction. The relative avidity of the non-pelleted membrane of $\mathrm{IgG}_{1}$ seemed to correlate with its high specific activity for $5^{\prime}$-nucleotidase. It may be argued that these quantitative differences are solely due to the quality of the membrane purification and to the quantity of the residual protein. However, this does not account for the findings that insulin binds to both membrane fractions while the transferrin and IgM bind only to the pelleted membrane fraction. Further, the problem of membrane aggregation, although difficult to estimate, was not considered to be significantly affecting the sucrose gradient results because each membrane fraction possessed reproducible characteristics with respect to protein binding and $5^{\prime}$-nucleotidase activity.

It is possible that the relatively greater binding of $\mathrm{IgG}_{1}$ to the lighter fraction of membrane might be due to the $\mathrm{Fc}$ receptors in the pellet fraction being saturated with endogenously bound IgG. It is difficult to answer this problem in the light of current knowledge but immunoglobulin light chain bands could not be detected in the SDS-polyacrylamide gel experiments. The lack of detectable antibody protein in the pellet fraction shows that it was not present, complexed to $\mathrm{Fc}$ receptors, in quantities sufficient to precipitate antibody-bound membrane as the pelleted membrane fraction, leaving the light fraction to bind the ${ }^{125} \mathrm{I}-$ labelled $\mathrm{IgG}_{1}$.

It therefore seems probable that a separation has been made between two somewhat different 
fractions of microvillous membrane. It is highly probable that both fractions come from the microvillous brush border since the method of the initial extraction of PVM is very gentle and contaminating blood and other cells are removed by the early centrifugation steps. Nelson, Smith \& Jarrett (1978) have reported that membrane receptors for insulin have a non-uniform distribution on the maternal aspect of the trophoblast, being associated with the distal ends of the microvilli. This is in contrast to the distribution of IgG receptors which are found on the microvillous and inter-microvillous membrane (King, 1977). It is not known whether these histological findings correlate with the heterogeneity reported in the present results. Other factors, such as patterns of ageing of the trophoblast and its associated brush border, could also be involved.

This work was supported by a grant from the Medical Research Council. We thank Mr Jim Aitken for help with electron microscopy and photography and Miss Bruce and the Sisters and Nursing Staff of the Labour Suite of the Queen Mother's Hospital, Yorkhill, Glasgow, for co-operation.

\section{References}

Balfour, A.H. \& Jones, E.A. (1977) The binding of plasma proteins to human placental cell membranes. Clin. Sci. Mol. Med. 52, 383-394.

Carlson, R. W., Wada, H.G. \& Sussman, H.H. (1976) The plasma membrane of the human placenta. Isolation of microvillous membrane and characterization of protein and glycoprotein subunits. J. biol. Chem. 251, 4139-4146.

Currie, G.A. \& Bagshawe, K.D. (1967) The masking of antigens on trophoblast and cancer cells. Lancet i, $707-710$.

Faulk, W.P. \& Galbraith, G.M.P. (1979) Trophoblast transferrin and transferrin receptors in the hostparasite relationship of human pregnancy. Proc. $R$. Soc. $B$ 204, 83-97.

Faulk, W.P., Jeannet, M., Creighton, W.D. \& Carbonara, A. (1974) Immunological studies of the human placenta. Characterization of immunoglobulins on trophoblastic basement membrane. J. clin. Invest. 54, 1011-1019.

Franklin, E.C. (1960) Structural units of human 7S gamma globulin. J. clin. Invest. 39, 1933-1941.

Goodfellow, P.N., Barnstable, C.J., Bodmer, W.F., Snary, D. \& Crumpton, M.J. (1976) Expression of HLA system antigens on placenta. Transplantation 22, 595-603.

Harrison, L.C., Billington, T., Clark, S., Nichols, R., East, I. \& Martin, F.I.R. (1977) Decreased binding of insulin by receptors on placental membrane from diabetic mothers. J. clin. Endocr. Metab. 44, 206209.

Harrison, L.C., Billington, T., East, I.J., Nichols, R.J. \& Clark, S. (1978) The effect of solubilization on the properties of the insulin receptor of human placental membrane. Endocrinology 102, 1485-1495.

Heide, K. \& Schwick, H.G. (1978) Salt fractionation of immunoglobulins. In Handbook of Experimental Immunology, Vol. 1, pp. 7.1-7.11. Ed. D. M. Weir. Blackwell Scientific Publications, Edinburgh.

Hunter, W.H. \& Greenwood, F.C. (1962) Preparation of Iodine-131 labelled human growth hormone of high specific activity. Nature, Lond. 194, 495-496.

King, B.F. (1977) In vitro adsorption of peroxidaseconjugated $\operatorname{IgG}$ by human placental villi. Anat. Rec. $187,624-625$.
Laemmli, U.K. (1970) Cleavage of structural proteins during the assembly of the head of bacteriophage T4. Nature, Lond. 227, 680-685.

Lowry, O.H., Rosebrough, N.J., Farr, A.L. \& Randall, R.J. (1951) Protein measurement with the folin phenol reagent. J. biol. Chem. 193, 265-275.

Marshall, R.N., Underwood, L.E., Voina, S.G., Foushee, D.B. \& Van Wyk, J.J. (1974) Characterization of the insulin and somatomedin $\mathrm{C}$ receptors in human placental cell membrane. J. clin. Endocr. Metab. 39, 283-292.

Matre, R., Tonder, O. \& Endresen, C. (1975) Fc receptors in human placenta. Scand. J. Immunol. 4, 741-745.

McNabb, T., Koh, T.Y., Dorrington, K.J. \& Painter, R.H. (1976) Structure and function of immunoglobulin domains. V. Binding of immunoglobulin $\mathrm{G}$ and fragments to placental membrane preparations. $J$. Immunol. 117, 882-888.

Nelson, D.M., Smith, R.M. \& Jarrett, L. (1978) Nonuniform distribution and grouping of insulin receptors on the surface of human placental syncytial trophoblast. Diabetes 27, 530-538.

Ogbimi, A.O., Johnson, P.M., Brown, P.J. \& Fox, H. (1979) Characterization of the soluble fraction of human syncytiotrophoblast microvillous plasma membrane-associated proteins. $J$. Reprod. Immunol. 1, 127-140.

Porter, R.R. (1959) The hydrolysis of rabbit $\gamma$ globulin and antibodies with crystalline papain. Biochem. $J$. 73, 119-126.

Posner, B.I. (1974) Insulin receptors in human and animal placental tissue. Diabetes 23, 209-217.

Smith, N.C., Brush, M.G. \& Luckett, S. (1974) Preparation of human placental villous surface membrane. Nature, Lond. 252, 302-303.

Snary, D., Woods, F.R. \& Crumpton, M.J. (1976) Disruption of solid tissue for plasma membrane preparation. Analyt. Biochem. 74, 457-465.

Sutcliffe, R.G., Kukulska-Langlands, B.M., Coggins, J.R., Hunter, J.B. \& Gore, C.H. (1980) Studies on human pregnancy associated plasma protein-A. Biochem. J. 191, 799-809. 